\title{
Galectin-3, cardiac structure and function, and long-term mortality in patients with acutely decompensated heart failure
}

\author{
Ravi V. Shah ${ }^{1}$, Annabel A. Chen-Tournoux ${ }^{1}$, Michael H. Picard ${ }^{1}$, \\ Roland R. J. van Kimmenade ${ }^{2}$, and James L. Januzzi ${ }^{1 *}$ \\ ${ }^{1}$ Cardiology Division, Department of Medicine, Massachusetts General Hospital, Harvard Medical School, 32 Fruit Street, Yawkey 5984, Boston, MA 02114, USA; and ${ }^{2}$ Department \\ of Cardiology, University Hospital Maastricht, Maastricht, The Netherlands
}

Received 21 January 2010; revised 20 March 2010; accepted 23 March 2010; online publish-ahead-of-print 5 June 2010

\begin{abstract}
Aims
To determine the relationship between galectin-3 concentrations and cardiac structure in patients with acute dyspnoea, and to evaluate the impact of galectin-3 independent of echocardiographic measurements on long-term mortality.

Methods

and results

One hundred and fifteen patients presenting to the emergency department with acute dyspnoea who had galectin-3 levels and detailed echocardiographic studies on admission were studied. Galectin-3 levels were associated with older age $(r=0.26, P=0.006)$, lower creatinine clearance $(r=-0.42, P<0.001)$, and higher levels of $N$-terminal-proBNP $(r=0.39, P<0.001)$. Higher galectin-3 levels were associated with tissue Doppler $E / E_{\mathrm{a}}$ ratio $(r=0.35, P=0.01)$, a lower right ventricular (RV) fractional area change $(r=-0.19, P=0.05)$, higher RV systolic pressure $(r=0.37$, $P<0.001)$, and more severe mitral $(r=0.30, P=0.001)$ or tricuspid regurgitation $(r=0.26, P=0.005)$. In patients diagnosed with heart failure (HF), the association between galectin-3 and valvular regurgitation and RV systolic pressure persisted. In a multivariate Cox regression model, galectin-3 remained a significant predictor of 4-year mortality independent of echocardiographic markers of risk. Dyspnoeic patients with HF and galectin-3 levels above the median value had a $63 \%$ mortality; patients less than the median value had a $37 \%$ mortality $(P=0.003)$.
\end{abstract}

Conclusion

Among dyspnoeic patients with and without ADHF, galectin-3 concentrations are associated with echocardiographic markers of ventricular function. In patients with ADHF, a single admission galectin-3 level predicts mortality to 4 years, independent of echocardiographic markers of disease severity.

Keywords Heart failure • Echocardiography • Prognosis

\section{Introduction}

Hospitalization for acutely decompensated heart failure (ADHF) represents a sentinel prognostic event in the development or progression of chronic heart failure (HF), with poor short and longer term post-discharge survival rates. ${ }^{1}$ From a physiological perspective, an ideal strategy for prognostication in ADHF would include not only biomarkers of mechanical stretch and ischaemia, but also markers of inflammation and remodelling. ${ }^{2-4}$ Changes in cardiac structure and function usually precede symptoms, can be difficult to predict clinically, and may require specialized imaging that is not always available (e.g. cardiac magnetic resonance imaging) ${ }^{5}$

Galectin-3, a $\beta$-galactoside-binding lectin over expressed by macrophages during phagocytosis, is up-regulated in cardiacresident macrophages in hypertrophied rat myocardium, even before the onset of frank HF. ${ }^{6}$ Furthermore, intrapericardial administration of galectin-3 promotes a pro-fibrotic phenotype., ${ }^{7,8}$ Despite recent clinical results suggesting that serum galectin-3 levels are higher in patients with ADHF, and are independent of and additive to NT-proBNP in predicting short-term mortality in this setting, ${ }^{9}$ nothing is known regarding correlates of cardiac

*Corresponding author. Tel: +1 617726 3443, Fax: +1 617643 1620, Email: jjanuzzi@partners.org

Published on behalf of the European Society of Cardiology. All rights reserved. (C) The Author 2010. For permissions please email: journals.permissions@oxfordjournals.org. 
structure and function and galectin-3 values. Accordingly, we examined associations between galectin-3 levels, cardiac structure and function, and outcomes among patients with ADHF enrolled in the Pro-BNP Investigation of Dyspnoea in the Emergency Department (PRIDE) study. ${ }^{10}$

\section{Methods}

\section{Patient population}

The design and main results of the PRIDE study are described elsewhere. ${ }^{10}$ PRIDE was a prospective, blinded study of 599 dyspnoeic patients presenting to the emergency department of the Massachusetts General Hospital, which aimed to evaluate the utility of NT-proBNP testing compared with clinical judgement for the diagnosis of ADHF. To determine relationships between galectin-3 levels and cardiac structure, a subset of 115 patients from the overall cohort who underwent detailed echocardiographic examinations and had galectin-3 levels measured during the index admission were studied. Of these 115 patients, 76 were ultimately diagnosed with ADHF. Follow-up for outcomes was available in $100 \%$ of the present cohort. Patient outcome with respect to mortality was assessed via a Social Security Death Index database search.

\section{Echocardiography}

Transthoracic echocardiography was performed during the index hospitalization at the discretion of the managing physician with standard techniques as described previously. ${ }^{11}$ The median time between hospital contact and echocardiography in these patients was $45 \mathrm{~h}$ (interquartile range $23-73 \mathrm{~h}$ ). Off-line analysis was performed by observers blinded to the patients' clinical and biomarker data. Structural indices assessed on echocardiography included left ventricular (LV) enddiastolic and end-systolic volume, LV wall thickness, LV mass, left atrial volume index, and right ventricular (RV) end-diastolic and endsystolic area. Left ventricular ejection fraction was determined from the LV volumes using biplane modified Simpson's measurements. Markers of diastolic function included early and late transmitral diastolic velocities ( $E$ and $A$ ); early deceleration time, and early and late diastolic tissue Doppler velocities at the lateral mitral annulus $\left(E_{\mathrm{a}}\right.$ and $A_{a}$ ). Indices of RV function included RV fractional area change; the presence or absence of RV hypokinesis or dilation by visual assessment; and tricuspid regurgitation (TR) velocity. Mitral regurgitation $(M R)$ and TR severity were graded from 0 (none) to 4 (severe) on the basis of visual assessment of structural and Doppler parameters as described previously. ${ }^{11}$ Right ventricular systolic pressure was calculated from the maximum TR velocity using the Bernoulli equation. ${ }^{11}$ Measurements were averaged over three cycles (five if atrial fibrillation was present). Since all echocardiographic measurements were not available for all patients, analyses were based on the echocardiographic data available.

\section{Galectin-3 and NT-proBNP analysis}

Blood collected at the time of presentation was analysed for concentrations of galectin-3 using a novel, enzyme-linked immunosorbent assay kit (BG Medicine, Inc., Waltham, MA, USA). This is a two-site immunoassay in which the capture antibody, a rat $\lg G 2$ a monoclonal antibody raised against mouse galectin-3 protein, is immobilized on 96-well plates. Calibration and standardization of the assay was performed according to the manufacturer's protocol. The intra-assay and inter-assay variances for galectin- 3 were 5.6 and $8.6 \%$, respectively. NT-proBNP levels were assayed as previously described. ${ }^{10}$

\section{Statistical analysis}

Association between log-transformed galectin-3 and echocardiographic and clinical indices was evaluated with Pearson or Spearman regression analysis. Furthermore, a subset of 76 patients with ADHF as the cause of acute dyspnoea who had undergone echocardiography during the index admission was analysed separately for association between galectin-3 levels and indices of cardiac structure. Cox multivariate regression analysis was performed to identify independent predictors of 4-year mortality in patients with ADHF using galectin-3 levels and echocardiographic measurements as covariates. Statistical analyses were conducted with the use of SAS software, version 9.1 (SAS Institute) and R software, version 2.6.

\section{Results}

\section{Baseline characteristics and clinical correlates of galectin-3}

Tables 1 and 2 detail the baseline clinical and echocardiographic characteristics for patients with both galectin-3 measurements and echocardiography performed during the index hospitalization, stratified by adjudicated cause of dyspnoea. Patients with a final diagnosis of ADHF were on average older, more likely to be diabetic, had poorer renal function, lower haemoglobin, and higher NT-proBNP, C-reactive protein, and galectin-3 levels, than patients without ADHF.

With regard to echocardiographic parameters, patients with ADHF had a more dilated, remodelled, hypertrophied LV with lower LV ejection fraction, a more dilated left atrium, and a higher prevalence of diastolic filling abnormalities than patients without ADHF. In addition, there was a higher incidence of pulmonary hypertension (as measured by RV systolic pressure) and mitral and tricuspid regurgitation in patients with ADHF.

Association between clinical covariates and galectin-3 concentrations was performed by Pearson regression analysis (Table 3). Higher levels of galectin-3 were significantly associated with more advanced age $(r=0.26, P=0.006)$, poorer renal function $(r=-0.42$ for Modified Diet in Renal Disease estimated glomerular filtration rate; $r=0.38$ for blood urea nitrogen, both $P<$ 0.001), higher NT-proBNP $(r=0.39, P<0.001)$ and higher $C$ reactive protein $(r=0.17, P=0.005)$. Galectin-3 levels were not associated with admission systolic or diastolic blood pressure or body mass index.

\section{Echocardiographic correlates of galectin-3 concentration}

Univariate linear regression analysis of echocardiographic indices and galectin-3 concentration is shown in Table 4. In patients with all-cause dyspnoea, although galectin-3 was not significantly related to markers of LV structure or systolic function, higher levels of galectin-3 were related to Doppler indices of higher filling pressure (higher $E / E_{a}$ ratio) and more extensive diastolic relaxation abnormalities (lower $E_{a}$ velocity). In addition, there was a striking relationship between higher levels of galectin-3 and poorer RV systolic function (lower RV fractional area change), a higher RV systolic pressure and more severe mitral and TR. 
Table I Baseline characteristics of PRIDE subjects with galectin-3 and echocardiographic measurements available $(n=115)$

\begin{tabular}{|c|c|c|c|}
\hline Characteristic & Patients with ADHF $(n=76)$ & Patients without ADHF $(n=39)$ & $P$-value \\
\hline Age (mean, SD) & $71.6(13.6)$ & $65.2(12.8)$ & 0.02 \\
\hline Male, \% & $50 \%$ & $56 \%$ & 0.65 \\
\hline Hypertension, \% & $66 \%$ & $56 \%$ & 0.44 \\
\hline Coronary artery disease, $\%$ & $33 \%$ & $26 \%$ & 0.56 \\
\hline Diabetes mellitus, \% & $41 \%$ & $13 \%$ & $<0.001$ \\
\hline Chronic obstructive lung disease, \% & $25 \%$ & $28 \%$ & 0.88 \\
\hline Prior HF, \% & $42 \%$ & $23 \%$ & 0.07 \\
\hline Orthopnoea, \% & $29 \%$ & $15 \%$ & 0.17 \\
\hline Paroxysmal nocturnal dyspnoea, \% & $20 \%$ & $18 \%$ & 0.98 \\
\hline History of cardiomyopathy, \% & $15 \%$ & $8 \%$ & 0.45 \\
\hline \multicolumn{4}{|l|}{ NYHA functional class } \\
\hline Class I, \% & $0 \%$ & $18 \%$ & 0.01 \\
\hline Class II, \% & $20 \%$ & $32 \%$ & 0.26 \\
\hline Class III, \% & $29 \%$ & $29 \%$ & 0.86 \\
\hline Class IV, \% & $51 \%$ & $21 \%$ & 0.005 \\
\hline Beta-blocker, \% & $55 \%$ & $41 \%$ & 0.21 \\
\hline Loop diuretic, \% & $49 \%$ & $23 \%$ & 0.01 \\
\hline Angiotensin converting enzyme inhibitor, \% & $38 \%$ & $13 \%$ & 0.01 \\
\hline Angiotensin receptor blocker, \% & $8 \%$ & $5 \%$ & 0.87 \\
\hline Digoxin, \% & $26 \%$ & $8 \%$ & 0.03 \\
\hline Heart rate (mean, SD) & $90.3(27.2)$ & $87.2(28.0)$ & 0.58 \\
\hline Respiratory rate (mean, SD) & $26.0(14.3)$ & $21.7(5.1)$ & 0.03 \\
\hline Systolic blood pressure (mean, SD) & $141.3(29.4)$ & $137.5(22.7)$ & 0.44 \\
\hline Body mass index (mean, SD) & $28.1(5.6)$ & $28.6(5.6)$ & 0.62 \\
\hline Jugular venous distension, $\%$ & $16 \%$ & $8 \%$ & 0.35 \\
\hline Rales, \% & $51 \%$ & $10 \%$ & $<0.001$ \\
\hline Oedema, \% & $40 \%$ & $23 \%$ & 0.12 \\
\hline Serum creatinine (mean, SD) & $1.29(0.45)$ & $1.07(0.37)$ & 0.01 \\
\hline Blood urea nitrogen (mean, SD) & $25.7(12.2)$ & $19.9(12.6)$ & 0.02 \\
\hline NT-proBNP (median, IQR) & 4493 (1920-9999) & $390(151-1191)$ & $<0.001$ \\
\hline C-reactive protein (median, IQR) & $20.9(6.1-60.1)$ & $11.7(2.7-28.0)$ & 0.03 \\
\hline Estimated GFR (mean, SD) & $60.0(27.3)$ & $74.3(28.4)$ & 0.01 \\
\hline Galectin-3 (median, IQR) & $15.0(11.1-19.7)$ & $11.0(9.1-14.4)$ & 0.006 \\
\hline Haemoglobin (mean, SD) & $12.1(2.4)$ & $13.2(2.8)$ & 0.06 \\
\hline Lower extremity oedema, \% & $33 \%$ & $13 \%$ & 0.04 \\
\hline Death within 4 years (\%) & $50 \%$ & $33 \%$ & 0.13 \\
\hline
\end{tabular}

\section{Galectin-3 and long-term mortality in ADHF in patients with echocardiography}

In the 115 patients investigated in this study, galectin-3 levels were higher in patients who had died at 1 year $(P=0.003$; Figure $1 A)$ and at 4 years $(P<0.001$; Figure $1 B)$ as compared with patients who survived. To determine the impact of galectin-3 levels on 4-year mortality independent of traditional echocardiographic markers of cardiac structure and function, we conducted a multivariate Cox regression analysis including several echocardiographic indices and galectin-3 levels (Table 5). We considered four-chamber LV volumes and dimensions, LV ejection fraction, LV mass, LA volume, RV fractional area change, transmitral $E$ wave velocity, RV systolic pressure, and quartiles of galectin-3. Only patients with all echocardiographic indices available were included in the Cox analysis $(n=53)$. Of these variables, the highest levels of galectin-3 were most strongly associated with a higher risk of 4-year mortality, independent of LV dimensions, function, or RV pressures. Furthermore, galectin-3 remained an independent predictor of 4-year mortality when modelled as a log-transformed, continuous variable [hazard ratio (HR) 14.5, 95\% confidence interval (Cl) 3.1-67.5, $P=0.001$ ] or per median level (patients with galectin-3 level $>14.97 \mathrm{ng} / \mathrm{mL}$ median value, $\mathrm{HR}=5.5,95 \% \mathrm{Cl}$ $2.0-15.0, P=0.001)$. 
Table 2 Baseline echocardiographic characteristics of PRIDE subjects with galectin-3 and echocardiographic measurements $(n=115)^{\mathrm{a}}$

\begin{tabular}{|c|c|c|c|}
\hline Variable & $\begin{array}{l}\text { Patients } \\
\text { with ADHF } \\
(n=76)\end{array}$ & $\begin{array}{l}\text { Patients } \\
\text { without } \\
\text { ADHF } \\
(n=39)\end{array}$ & $P$-value \\
\hline \multicolumn{4}{|c|}{ LV area and volumes (4 chamber) } \\
\hline LV end-diastolic area & $30.8(7.9)$ & $26.4(6.0)$ & 0.002 \\
\hline LV end-systolic area & $22(8.2)$ & $16(5.5)$ & $<0.001$ \\
\hline LV end-systolic volume & $65.3(38.2)$ & $37.9(22.1)$ & $<0.001$ \\
\hline LV end-diastolic volume & $109(43.5)$ & $84.5(30.8)$ & 0.001 \\
\hline $\begin{array}{l}\text { LV end-diastolic dimension } \\
\qquad(\mathrm{mm})\end{array}$ & $49.5(9.3)$ & $45.9(5.9)$ & 0.017 \\
\hline $\begin{array}{l}\text { LV end-systolic dimension } \\
\quad(\mathrm{mm})\end{array}$ & $36.9(11.5)$ & $29.6(5.3)$ & $<0.001$ \\
\hline LV ejection fraction (\%) & $45.5(15)$ & $57.2(9.9)$ & $<0.001$ \\
\hline Septal thickness (mm) & $11.3(2.4)$ & $11.1(2.0)$ & 0.69 \\
\hline LV mass index $\left(\mathrm{g} / \mathrm{m}^{2}\right)$ & $106.2(34.9)$ & $88.9(25.5)$ & 0.005 \\
\hline LV hypertrophy, \% & $17 \%$ & $21 \%$ & 0.82 \\
\hline LA volume index $\left(\mathrm{mL} / \mathrm{m}^{2}\right)$ & $42.6(23.4)$ & $26.2(8.4)$ & $<0.001$ \\
\hline RV dilation & $16 \%$ & $14 \%$ & 0.95 \\
\hline $\mathrm{RV}$ fractional area change & $38.5(11.8)$ & $41.2(10.0)$ & 0.23 \\
\hline \multicolumn{4}{|l|}{ Mitral inflow parameters } \\
\hline$E$ peak velocity $(\mathrm{cm} / \mathrm{s})$ & $101.1(34.8)$ & $73.3(23.8)$ & $<0.001$ \\
\hline A peak velocity $(\mathrm{cm} / \mathrm{s})$ & $71.7(36.6)$ & $67.1(21.4)$ & 0.52 \\
\hline E/A ratio & $1.7(0.9)$ & $1.2(0.5)$ & 0.006 \\
\hline E deceleration slope & $636.9(261.7)$ & $428.6(217.9)$ & $<0.001$ \\
\hline E deceleration time (ms) & $167(72.1)$ & $179.4(52.8)$ & 0.34 \\
\hline$E_{\mathrm{a}}$ peak velocity $(\mathrm{cm} / \mathrm{s})$ & $8.1(2.9)$ & $9.1(2.3)$ & 0.11 \\
\hline$A_{a}$ peak velocity $(\mathrm{cm} / \mathrm{s})$ & $6.7(3.0)$ & $9.9(3.5)$ & 0.001 \\
\hline$E / E_{\mathrm{a}}$ ratio & $12.3(6.0)$ & $8.5(2.9)$ & 0.005 \\
\hline$E_{\mathrm{a}} / A_{\mathrm{a}}$ ratio & $1.4(0.9)$ & $1(0.5)$ & 0.04 \\
\hline \multicolumn{4}{|l|}{ Pulmonary inflow parameters } \\
\hline PV S peak velocity $(\mathrm{cm} / \mathrm{s})$ & $40.2(17.8)$ & $51.1(17.2)$ & 0.007 \\
\hline $\begin{array}{l}\text { PV S deceleration slope } \\
\left(\mathrm{cm} / \mathrm{s}^{2}\right)\end{array}$ & $193.7(116.0)$ & $204.1(96.6)$ & 0.66 \\
\hline $\begin{array}{l}\text { PV S deceleration time } \\
\quad(\mathrm{ms})\end{array}$ & $204.4(78.5)$ & $249.1(96.0)$ & 0.03 \\
\hline PV D peak velocity $(\mathrm{cm} / \mathrm{s})$ & $59.1(21.8)$ & $47.5(15.7)$ & 0.006 \\
\hline $\begin{array}{l}\text { PV D deceleration slope } \\
\left(\mathrm{cm} / \mathrm{s}^{2}\right)\end{array}$ & $345.6(242.0)$ & $210.3(121.8)$ & 0.001 \\
\hline $\begin{array}{l}\text { PV D deceleration time } \\
(\mathrm{ms})\end{array}$ & $191.4(90.6)$ & $213.4(67.6)$ & 0.21 \\
\hline$P V S: D$ ratio & $2.6(3.4)$ & $1.2(1.1)$ & 0.009 \\
\hline $\begin{array}{l}\text { PA } S \text { acceleration velocity } \\
(\mathrm{cm} / \mathrm{s})\end{array}$ & $1175.6(516)$ & $1287.5(540)$ & 0.34 \\
\hline $\begin{array}{l}\text { PA S acceleration time } \\
\quad(\mathrm{ms})\end{array}$ & $74.3(25.4)$ & $79.4(31.3)$ & 0.43 \\
\hline \multicolumn{4}{|l|}{ Tricuspid regurgitation (TR) } \\
\hline No TR & $5.3 \%$ & $10.3 \%$ & 0.54 \\
\hline $1+\mathrm{TR}$ & $27.6 \%$ & $53.8 \%$ & 0.01 \\
\hline $2+T R$ & $21.1 \%$ & $25.6 \%$ & 0.75 \\
\hline $3+T R$ & $35.5 \%$ & $10.3 \%$ & 0.008 \\
\hline $4+T R$ & $10.5 \%$ & $0.0 \%$ & 0.09 \\
\hline
\end{tabular}

Table 2 Continued

\begin{tabular}{|c|c|c|c|}
\hline Variable & $\begin{array}{l}\text { Patients } \\
\text { with ADHF } \\
(n=76)\end{array}$ & $\begin{array}{l}\text { Patients } \\
\text { without } \\
\text { ADHF } \\
(n=39)\end{array}$ & $P$-value \\
\hline $\begin{array}{l}\text { RV systolic pressure } \\
\qquad(\mathrm{mmHg})\end{array}$ & $49.4(12.6)$ & $38.3(11.4)$ & $<0.001$ \\
\hline \multicolumn{4}{|c|}{ Mitral regurgitation (MR) } \\
\hline No MR & $0.0 \%$ & $2.6 \%$ & 0.72 \\
\hline $1+M R$ & $23.7 \%$ & $50.0 \%$ & 0.009 \\
\hline $2+M R$ & $28.9 \%$ & $31.6 \%$ & 0.94 \\
\hline $3+M R$ & $39.5 \%$ & $13.2 \%$ & 0.008 \\
\hline $4+M R$ & $7.9 \%$ & $2.6 \%$ & 0.49 \\
\hline \multicolumn{4}{|c|}{ Aortic insufficiency (Al) } \\
\hline No Al & $36.0 \%$ & $62.2 \%$ & 0.02 \\
\hline $1+\mathrm{Al}$ & $32.0 \%$ & $21.6 \%$ & 0.36 \\
\hline $2+\mathrm{Al}$ & $24.0 \%$ & $16.2 \%$ & 0.48 \\
\hline $3+\mathrm{Al}$ & $5.3 \%$ & $0.0 \%$ & 0.37 \\
\hline $4+\mathrm{Al}$ & $2.7 \%$ & $0.0 \%$ & 0.81 \\
\hline
\end{tabular}

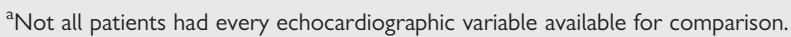
$\mathrm{ADHF}$, acutely decompensated heart failure.

Table 3 Univariate correlation analysis between clinical and biochemical indices and galectin-3 concentrations in patients with acute dyspnoea $(n=115)$

\begin{tabular}{lcc}
\hline Characteristic & $\boldsymbol{r}$ (Pearson) & $\boldsymbol{P}$-value \\
$\ldots \ldots \ldots \ldots \ldots \ldots \ldots \ldots \ldots \ldots \ldots \ldots \ldots \ldots \ldots \ldots \ldots \ldots \ldots \ldots \ldots \ldots \ldots \ldots \ldots \ldots \ldots \ldots \ldots \ldots \ldots \ldots \ldots \ldots$ \\
Age & 0.26 & 0.006 \\
Systolic blood pressure & -0.03 & 0.78 \\
Diastolic blood pressure & -0.02 & 0.87 \\
Body mass index & -0.04 & 0.69 \\
Creatinine clearance & -0.42 & $<0.001$ \\
Blood urea nitrogen & 0.38 & $<0.001$ \\
N-terminal proBNP & 0.39 & $<0.001$ \\
C-reactive protein & 0.26 & 0.005 \\
\hline
\end{tabular}

\section{Discussion}

The role of galectin-3 (a $\beta$-galactoside-binding lectin macrophage product) in HF was initially described in rat models, in which galectin-3 expression was found to be up-regulated in endomyocardial biopsies of rats with cardiac hypertrophy that subsequently progressed to HF. ${ }^{6}$ Mechanistically, galectin-3 is a product of active macrophages, with binding sites on cardiac-resident fibroblasts, leading to an increase in myocardial collagen expression and interstitial fibrosis, transforming growth factor- $\beta$ activation, and subsequent LV dysfunction. ${ }^{6-8}$ Accordingly, galectin-3 may play a pivotal role in the response to injury and inflammation during $\mathrm{HF}$, including being an important part of ventricular remodelling.

There are limited clinical data on galectin-3 in HF., ${ }^{9,12}$ We previously showed that elevated levels of galectin- 3 on admission 
Table 4 Univariate correlation analysis of galectin-3 vs. echocardiographic indices in patients with acute dyspnoea $(n=115)$

\begin{tabular}{|c|c|c|}
\hline Characteristic & $r$ (Spearman) & $P$-value \\
\hline \multicolumn{3}{|l|}{ Left ventricular (LV) parameters } \\
\hline \multicolumn{3}{|c|}{ LV areas and volumes (4 chamber view) } \\
\hline LV end-diastolic area & 0.003 & 0.98 \\
\hline LV end-systolic area & 0.075 & 0.45 \\
\hline LV end-diastolic volume & 0.024 & 0.81 \\
\hline LV end-systolic volume & 0.095 & 0.33 \\
\hline LV mass index & 0.059 & 0.55 \\
\hline LV end-diastolic dimension & 0.040 & 0.68 \\
\hline LV end-systolic dimension & 0.081 & 0.40 \\
\hline Septal thickness & -0.033 & 0.73 \\
\hline Posterior wall thickness & -0.164 & 0.09 \\
\hline LV ejection fraction & -0.139 & 0.15 \\
\hline \multicolumn{3}{|l|}{ LV diastolic parameters } \\
\hline \multicolumn{3}{|l|}{ Transmitral flow } \\
\hline E peak velocity & 0.191 & 0.06 \\
\hline A peak velocity & 0.103 & 0.40 \\
\hline E/A ratio & 0.069 & 0.57 \\
\hline$E$ deceleration time & -0.008 & 0.94 \\
\hline$E_{\mathrm{a}}$ peak velocity & -0.246 & 0.03 \\
\hline$A_{a}$ peak velocity & -0.205 & 0.13 \\
\hline$E / E_{\mathrm{a}}$ ratio & 0.345 & 0.01 \\
\hline$E_{\mathrm{a}} / A_{\mathrm{a}}$ ratio & -0.082 & 0.55 \\
\hline \multicolumn{3}{|l|}{ Left atrial (LA) parameters } \\
\hline LA volume (4 chamber) & -0.016 & 0.87 \\
\hline LA volume (2 chamber) & 0.020 & 0.84 \\
\hline LA volume index & 0.047 & 0.65 \\
\hline \multicolumn{3}{|l|}{ Right ventricular (RV) parameters } \\
\hline RV end-diastolic area & -0.026 & 0.79 \\
\hline RV end-systolic area & 0.085 & 0.39 \\
\hline RV end-diastolic volume & -0.005 & 0.96 \\
\hline RV end-systolic volume & 0.037 & 0.71 \\
\hline $\mathrm{RV}$ fractional area change & -0.193 & 0.05 \\
\hline RV systolic pressure & 0.366 & $<0.001$ \\
\hline Tricuspid regurgitant jet velocity & 0.304 & 0.003 \\
\hline \multicolumn{3}{|l|}{ Valvular disease } \\
\hline Tricuspid regurgitation severity & 0.258 & 0.005 \\
\hline Mitral regurgitation severity & 0.297 & 0.001 \\
\hline Aortic regurgitation severity & 0.115 & 0.23 \\
\hline
\end{tabular}

predicted 60-day mortality better than NT-proBNP, and were additive to NT-proBNP in predicting death at 60 days. ${ }^{9}$ Given mechanistic data in animal models implicating galectin-3 in cardiac remodelling and LV dysfunction, identifying associations between galectin-3 levels and cardiac structure and function is critically important. Furthermore, with the development of a novel assay for galectin-3, we elected to extend our observations with more in-depth mechanistic analyses of cardiac structure and function using this assay, along with an extension of the prognostic understanding of galectin-3.
In this study of dyspnoeic patients with and without ADHF, galectin-3 levels were significantly associated with echocardiographic markers of LV filling and diastolic function, valvular regurgitation, and RV function, as well as poorer renal function and an enhanced neurohormonal and inflammatory state (NT-proBNP and C-reactive protein, respectively). In addition, galectin-3 predicted the risk of long-term, 4-year mortality independent of echocardiographic markers of risk.

In the context of a putative mechanistic role for galectin-3 in mediating cardiac and vascular stiffness via collagen deposition, the associations found between galectin- 3 and advanced age and more decompensated renal function are not surprising. Advanced age and chronic kidney disease are strongly associated with increasing arterial stiffness, ${ }^{13}$ which itself has been linked to higher cardiovascular mortality. ${ }^{13,14}$ Furthermore, in a murine model, galectin-3 overexpression itself has been shown to promote renal fibrosis via activation of local fibroblasts, ${ }^{15}$ in a mechanism analogous to cardiac fibrosis. Given that we found blood urea nitrogen to be a powerful predictor of galectin-3 levels, independent of age, gender, blood pressure, or neurohormonal activation, circulating galectin-3 may actually worsen HF not only via a direct cardiotoxic effect, but may more importantly drive acute kidney injury as a mediator of cardiorenal physiology. In addition, the concordant relationship between galectin-3 and C-reactive protein is in line with recent data suggesting anti-inflammatory peptides may reduce galectin-3 expression in mice with angiotensin-II mediated hypertension and vascular damage. $^{16}$

Given the link between cardiac fibrosis, hypertrophy, and HF in animal models, it is of note that in our small cohort of patients with acute dyspnoea with and without HF, we found several associations between LV structure and function and galectin-3 concentrations. Without question, a follow-up echocardiogram might have further elucidated associations between galectin-3 and changes in such measurements, as is seen in remodelling. Nevertheless, we did observe significant relationships between higher galectin-3 levels and a higher LV filling pressures (as reflected in the $E / E_{a}$ ratio), as well as more extensive diastolic relaxation abnormalities (as reflected in $E_{\mathrm{a}}$ velocity). These observations are consistent with a potential role for galectin-3 in mediating cardiac stiffness (thereby impeding diastolic filling) and potentially worsening renal function. Indeed, in a recent study examining aortic distensibility in patients with chronic kidney disease, patients with more advanced renal failure had similar reductions in tissue Doppler $E_{a}$ velocity and higher $E / E_{a}$ ratios without systolic dysfunction. $^{17}$

In addition to the LV abnormalities, we observed a striking relationship between indices of RV function and galectin-3 levels. Higher levels of galectin-3 were associated with poorer RV systolic function (as reflected in fractional area change), more severe TR, and higher RV systolic pressures. One explanation is that the changes in RV function observed during the ADHF hospitalization may reflect elevated LV filling pressures; thus, the association between galectin-3 levels and markers of poorer RV performance reflect similar associations between galectin-3 and elevated left sided pressures. It is also possible that similar processes occurring in the LV (remodelling, fibrosis, and hypertrophy) may be 

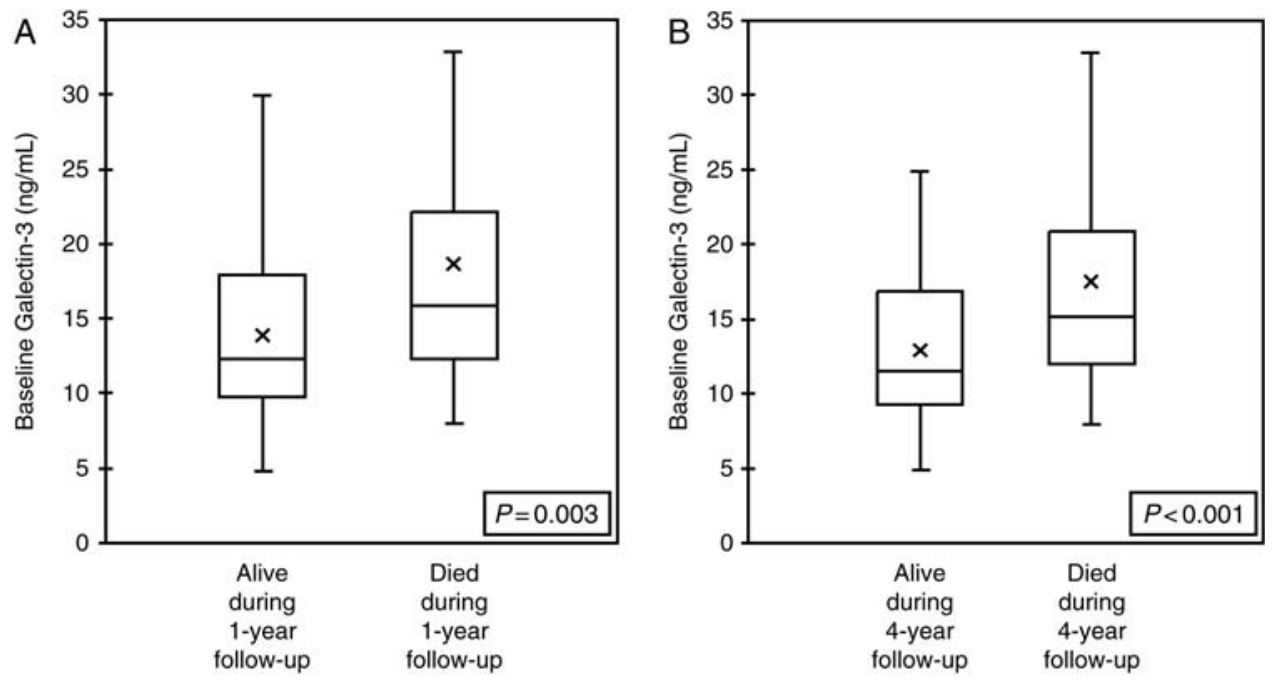

Figure I Galectin-3 in patients who died at 1 year $(A)$ and 4 years $(B)$ in all dyspnoeic patients $(n=115)$.

Table 5 Result of Cox multivariable regression for 4-year mortality in patients ultimately diagnosed with ADHF, including echocardiographic markers of cardiac structure and function ${ }^{\mathrm{a}}$

\begin{tabular}{|c|c|c|}
\hline Variable & Hazard ratio $(95 \% \mathrm{Cl})$ & $P$-value \\
\hline LV end-diastolic dimension & $0.81(0.69-0.95)$ & 0.01 \\
\hline LV end-systolic dimension & $1.24(1.08-1.41)$ & 0.002 \\
\hline LV ejection fraction & $1.17(1.03-1.21)$ & 0.01 \\
\hline RV systolic pressure & $1.05(1.00-1.09)$ & 0.03 \\
\hline Galectin-3 & $14.5(3.12-67.6)$ & 0.001 \\
\hline
\end{tabular}

${ }_{n} n=53$ patients were included in this analysis, all of whom had all covariates listed in text measured. Galectin-3 was treated as a log-transformed continuous variable.

occurring in the RV. Galectin-3 levels are increased in bronchoalveolar lavage fluid from patients with interstitial pulmonary fibrosis and pneumonia, suggesting another possibility linking galectin-3 levels to poorer pulmonary and RV function. ${ }^{18}$ The role of RV structure and function in short and longer term outcomes as well as remodelling in ADHF is underappreciated, and our data emphasize the potential importance of a better understanding of the importance of the RV in this context.

Our study has several important limitations. Echocardiography was obtained for clinical indications during the index admission, and there may have been delays between collection of biomarkers and echocardiograms. Since the biological half-life of galectin- 3 in our patient cohort is not known, it is also possible that relationships between echocardiographic indices and galectin-3 would have been different if both measures were taken simultaneously; however the process of myocardial fibrosis and remodelling (putatively reflected by galectin-3 concentrations) is not evanescent, and likely to have been reflected in associations between galectin-3 values on admission and echocardiographic findings. Although this study involved a small patient cohort, this population was carefully phenotyped with respect to clinical, echocardiographic, and biochemical indices. Given the limited number of patients in this study (especially in the cohort of patients with ADHF as a cause of dyspnoea), relationships between galectin-3 and echocardiographic variables are not necessarily definitive and should be viewed as hypothesis-generating for study in larger patient cohorts. In addition, the small patient cohort limited the study of galectin-3 in patients with HF and preserved vs. depressed LV systolic function. Given the proposed mechanism of galectin-3 in fibrosis, hypertrophy, and progressive cardiac failure, separate studies in patients with primarily HF with preserved ejection fraction should be undertaken.

The clinical and cardiac structural relationships with galectin-3 explored in this study provide the first indirect evidence in support of a potential role for galectin-3 in the pathogenesis of remodelling in $\mathrm{HF}$ in humans. The relationship between renal function, biomarkers of inflammation, and neurohormonal activation and galectin- 3 suggests a role for galectin- 3 in integrating these multiple mechanisms of worsening HF. In addition, the long-term prognostic importance of galectin-3 after echocardiographic indices are taken into account may identify a patient subset in whom these multiple mechanisms of cardiac dysfunction may be targeted to improve outcomes. Further research confirming the structural correlates observed in this study, as well as examining the impact of therapies aimed at cardiac and vascular remodelling (e.g. renin-angiotensin system blockade and aldosterone antagonism) on galectin-3 levels will be critical from a mechanistic and clinical perspective.

\section{Acknowledgements}

We would like to acknowledge the echocardiography laboratory at the Massachusetts General Hospital. 


\section{Funding}

This work was supported by the National Heart, Lung, and Blood Institute Heart Failure Research Network (R.V.S.; Boston, MA, USA), the Balson Scholar Fund (J.L.J); Boston, MA, USA), and the Interuniversity Cardiology Institute of the Netherlands (R.R.J.K.).

Conflict of interest: J.L.J. reports grant support from Roche Diagnostics, Siemens, Critical Diagnostics, and BG Medicine.

\section{References}

1. Bleumink GS, Knetsch AM, Sturkenboom MC, Straus SM, Hofman A, Deckers JW, Witteman JC, Stricker BH. Quantifying the heart failure epidemic: prevalence, incidence rate, lifetime risk and prognosis of heart failure The Rotterdam Study. Eur Heart J 2004;25:1614-1619.

2. Januzzi JL, van Kimmenade R, Lainchbury J, Bayes-Genis A, Ordonez-Llanos J, Santalo-Bel M, Pinto YM, Richards M. NT-proBNP testing for diagnosis and shortterm prognosis in acute destabilized heart failure: an international pooled analysis of 1256 patients. Eur Heart J 2006;27:330-337.

3. Peacock W, De Marco T, Fonarow GC, Diercks D, Wynne J, Apple FS, Wu AH, ADHERE Investigators. Cardiac troponin and outcome in acute heart failure. $N$ Engl J Med 2008;358:2117-2126.

4. Januzzi J, Peacock WF, Maisel AS, Chae CU, Jesse RL, Baggish AL, O'Donoghue M, Sakhuja R, Chen AA, van Kimmenade RR, Lewandrowski KB, Lloyd-Jones DM, Wu AH. Measurement of the interleukin family member ST2 in patients with acute dyspnea: results from the PRIDE (Pro-Brain Natriuretic Peptide Investigation of Dyspnea in the Emergency Department) study. J Am Coll Cardiol 2007;50:607-613.

5. Braunwald E. Biomarkers in heart failure. N Engl J Med 2008;358:2148-2159.

6. Sharma UC, Pokharel S, van Brakel TJ, van Berlo JH, Cleutjens JP, Schroen B, Andre S, Crijns HJ, Gabius JH, Maessen J, Pinto YM. Galectin-3 marks activated macrophages in failure-prone hypertrophied hearts and contributes to cardiac dysfunction. Circulation 2004;110:3121-3128.

7. Liu YH, D’Ambrosio M, Liu YD, Peng H, Rhaleb NE, Sharma U, Andre S, Gabius $\mathrm{H}$, Carretero $\mathrm{O}$. N-acetyl-seryl-aspartyl-lysyl-proline prevents cardiac remodeling and dysfunction induced by galectin-3, a mammalian adhesion/ growth-regulatory lectin. Am J Physiol Heart Circ Physiol 2009;296:H404-H412.

8. de Boer R, Voors A, Muntendam P et al Galectin-3: a novel mediator of heart failure development and progression. Eur J Heart Fail 2009;11:811-817.
9. van Kimmenade RJ, Januzzi J, Ellinor P, Sharma U, Bakker J, Low A, Martinez A, Crijns H, MacRae C, Menheere P, Pinto Y. Utility of amino-terminal pro-brain natriuretic peptide, galectin-3, and apelin for the evaluation of patients with acute heart failure. J Am Coll Cardiol 2006;48:1217-1224.

10. Januzzi JL Jr, Camargo CA, Anwaruddin S, Baggish AL, Chen AA, Krauser DG, Tung R, Cameron R, Nagurney JT, Chae CU, Lloyd-Jones DM, Brown DF, Foran-Melanson S, Sluss PM, Lee-Lewandrowski E, Lewandrowski KB. The NTerminal Pro-BNP Investigation of Dyspnea in the Emergency Department (PRIDE) study. Am J Cardiol 2005;95:948-954.

11. Chen A, Wood M, Krauser D, Baggish A, Tung R, Anwaruddin S, Picard M, Januzzi JL. NT-proBNP levels, echocardiographic findings, and outcomes in breathless patients: results from the ProBNP Investigation of Dyspnea in the Emergency Department (PRIDE) echocardiographic substudy. Eur Heart J 2006; 27:839-845

12. Milting $H$, Ellinghaus $P$, Seewald M, Cakar $H$, Bohms B, Kassner A, Korfer R, Klein M, Krahn T, Kruska L, Banayosy A, Kramer F. Plasma biomarkers of myocardial fibrosis and remodeling in terminal heart failure patients supported by mechanical circulatory support devices. I Heart Lung Transplant 2008;27: 589-596.

13. Blacher J, Guerin Am Pannier B, Marchais S, Safar M, London G. Impact of aortic stiffness on survival in end-stage renal disease. Circulation 1999;99: 2434-2439.

14. Mark P, Doyle A, Blyth K, Patel R, Weir R, Steedman T, Foster J, Dargie H, Jardine A. Vascular function assessed with cardiovascular magnetic resonance predicts survival in patients with advanced chronic kidney disease. J Cardiovasc Magn Reson 2006;10:39.

15. Henderson N, Mackinon A, Farnworth S, Kipari T, Haslett C, Iredale J, Liu FT, Hughes J, Sethi T. Galectin-3 expression and secretion links macrophages to the promotion of renal fibrosis. Am J Pathol 2008;172:288-298.

16. Sharma U, Rhaleb NE, Pokharel S, Harding P, Rasoul S, Peng H, Carretero O. Novel anti-inflmmatory mechanisms of $\mathrm{N}$-acteyl-ser-asp-lys-pro in hypertension-induced target organ damage. Am J Physiol Heart Circ Physiol 2008; 294: $\mathrm{H} 1226-\mathrm{H} 1232$.

17. Edwards N, Ferro C, Townend J, Steeds R. Aortic distensibility and arterialventricular coupling in early chronic kidney disease: a pattern resembling heart failure with preserved ejection fraction. Heart 2008;94:1038-1043.

18. Nishi Y, Sano H, Kawashima T, Okada T, Kuroda T, Kikkawa K, Kawashima S, Tanabe M, Goto T, Matsuzawa Y, Matsumura R, Tomioka H, Liu FT, Shirai K. Role of galectin-3 in human pulmonary fibrosis. Allergol Int 2007;56:57-65. 